\title{
The effects of a history of seizures during pregnancy on umbilical arterial blood gas values in pregnant women with epilepsy
}

\author{
Özhan Özdemir, Mustafa Erkan Sarı, Funda Arpacı Ertuğrul, Aslıhan Kurt, Vefa Selimova, Cemal Reşat Atalay \\ Department of Obstetrics and Gynecology, Ankara Numune Training and Education Hospital, Ankara, Turkey
}

\section{Abstract}

Objective: The objective of this study is to investigate if the number of seizures that occur during pregnancy has any effect on umbilical arterial blood gas values at delivery.

Material and Methods: In total, 55 women who were 37 to 41 weeks pregnant and diagnosed with generalized tonic-clonic epilepsy and 50 pregnant women with similar characteristics but not diagnosed as epileptic were included in this study. The patients diagnosed with epilepsy were divided into two groups: 27 patients with a history of at least 5 epileptic seizures during pregnancy and 28 who had no seizures during pregnancy. All patients diagnosed with epilepsy had a history of caesarean delivery or a caesarean section under general anesthesia on the advice of neurology. Pregnant women in the control group were also chosen from among patients who had a caesarean on account of a previous caesarean delivery. In the cases included in the study, umbilical arterial blood gas sampling was performed immediately after delivery.

Results: When the control group without epilepsy was compared with pregnant women who had no history of epileptic seizures during pregnancy, no difference was found in umbilical arterial blood gas values ( $p>0.05)$. When patients with a history of 5 or more epileptic seizures during pregnancy were compared with the control group without epilepsy and the patients with epilepsy who had no history of seizures during pregnancy, there was no statistically significant difference $(\mathrm{p}>0.05)$, although their umbilical arterial blood pH values were found to be lower, while partial carbon dioxide pressure $\left(\mathrm{pCO}_{2}\right)$, values were higher and partial oxygen pressure $\left(\mathrm{pO}_{2}\right)$ values were lower.

Conclusion: Taking potential fetal risks into consideration, maternal generalized tonic-clonic epileptic seizures might be worrying. Tonic-clonic seizures that occur during pregnancy appear to be associated with temporary hypoxia. Therefore, monotherapy for seizures and treatment at the lowest effective dose should be administered to women with epilepsy in the preconception and prenatal term.

(J Turk Ger Gynecol Assoc 2014; 15: 135-9)

Key words: Epilepsy, pregnancy, umbilical arterial blood gas

Received: 11 June, 2014

Accepted: 21 July, 2014

\section{Introduction}

Advances in the diagnosis of and treatment for epilepsy have allowed many women with epilepsy to lead a normal life and to conceive. Today, epilepsy is the most common neurological disorder during pregnancy, after migraine. Comprehensive epidemiological studies reveal that the prevalence of epilepsy is $6.8 \%$, and $0.3 \%$ to $0.5 \%$ of pregnancies are accompanied by epilepsy (1). Pregnant women with epilepsy are worried that antiepileptic drugs may have negative effects on the fetus, that convulsion frequency may increase, and that some health problems, including epilepsy, may occur in their children. Furthermore, it is known that antiepileptic drugs increase the risk of congenital malformation (2).

In women with epilepsy, such pregnancy complications as hyperemesis gravidarum, vaginal bleeding, preeclampsia, preterm birth, and postpartum bleeding are more common (3). Besides studies suggesting that seizures occurring in the first trimester increase malformation risk, there are also those that reject this idea (4). It has been indicated that central nervous system disorders, such as microcephaly, chronic static encephalopathy, and cerebral palsy, are more common in children affected by in utero seizures (5).

Generalized tonic-clonic seizures are harmful to the fetus due to an increase in blood pressure, oxygenation, and electrolyte changes during a seizure. Seizure-related traumas, spontaneous miscarriages, and intrauterine deaths may also occur (6). It has been shown in cardiotocography follow-ups that during term pregnancy, generalized tonic-clonic seizures lead to temporary fetal asphyxia. Fetal bradycardia, a decrease in variability, and decelerations may be observed for 15 minutes following a seizure (6).

Intrapartum assessment of umbilical cord arterial blood gas values is a decisive method of diagnosis in birth management. In addition, by giving a retrospective idea about fetal well-being at delivery, it contributes to the management of neonatal term and to decisions about possible attempts at 
Table 1. The distribution of age, gestation period (weeks), birth weight, and 5-minute Apgar scores

\begin{tabular}{|c|c|c|c|c|}
\hline Group & Age & $\begin{array}{l}\text { Gestation } \\
\text { Period }\end{array}$ & $\begin{array}{c}\text { Birth } \\
\text { Weight }\end{array}$ & $\begin{array}{c}5^{\text {th }} \text { minute } \\
\text { Apgar Scores }\end{array}$ \\
\hline Pregnant women with epilepsy who had no seizures $(n=28)$ & $26.4 \pm 6.1$ & $38.7 \pm 0.9$ & $3192.17 \pm 377.6$ & $8.2 \pm 0.3$ \\
\hline Pregnant women without epilepsy $(n=50)$ & $27.1 \pm 5.8$ & $38.6 \pm 1.2$ & $3211.43 \pm 364.2$ & $8.3 \pm 0.5$ \\
\hline
\end{tabular}

neonatal resuscitation in this term (7). Appearance, Pulse, Grimace, Activity, Respiration (APGAR) scoring might be beneficial in distinguishing normal neonates and the ones evidently exposed to hypoxia. However, this method of scoring is not sensitive enough to distinguish babies affected to a lesser extent by hypoxia (8). Thus, being an indicator of intrapartum condition during delivery and neonatal prognosis after delivery, umbilical cord $\mathrm{pH}$ values have been paid close attention in recent years. Our aim in this study is to explain whether epileptic seizures that occur during pregnancy are associated with antepartum asphyxia. For this purpose, we made use of umbilical arterial blood gas measurement as one of the most objective indicators of asphyxia.

\section{Material and Methods}

The study was conducted in Ankara Numune Education and Research Hospital. The protocol of the study was approved by the ethics committee of the hospital, and all participants signed an informed consent. In total, 55 women who were 37 to 41 weeks pregnant and diagnosed with generalized tonic-clonic epilepsy and 50 other pregnant women with similar characteristics but not diagnosed as epileptic were included in the study. All pregnant women with epilepsy were patients who had been diagnosed as epileptic by a neurology clinic before pregnancy. The mean age, mean gestation period (weeks), and mean birth weight of the patients included in the study were recorded.

The patients diagnosed with epilepsy were divided into two groups: 27 patients with a history of at least 5 epileptic seizures during pregnancy and 28 who did not have any seizures during pregnancy. All patients diagnosed with epilepsy had a history of caesarean delivery or a caesarean section under general anesthesia on the advice of neurology, and those who had a vaginal delivery were not included in the study in order to eliminate differences likely to arise from the mode of delivery. Pregnant women in the control group were also chosen from among patients who had an elective caesarean section because of a previous caesarean delivery.

In these cases, umbilical cord arterial blood gas sampling was performed immediately after delivery. Blood gases were analyzed within 30 minutes of birth by double-clamping a minimum 10-centimeter segment of cord within 5 minutes of birth and taking blood samples from the artery. To prevent blood from congealing in the syringes, heparinized blood gas syringes were used. The analyzer (ABL-2 Analyzer; Radiometer, Copenhagen, Denmark) was used to define blood gas parameters. Arterial $\mathrm{pH}$, partial carbon dioxide pressure $\left(\mathrm{pCO}_{2}\right)$, par- tial oxygen pressure $\left(\mathrm{pO}_{2}\right)$, bicarbonate levels $\left(\mathrm{HCO}_{3}\right)$, and base excess (BE) were measured separately by the analyzer.

Those who had maternal diseases, such as diabetes mellitus and hypertension, which are likely to cause uteroplacental insufficiency, and pregnancies complicated by intrauterine growth retardation and oligohydramnios were not included in the study. Patients with highly variable decelerations that had signs of fetal distress in fetal heart rate (less than 70 beats per minute over 60 seconds), those observed to have recurrent late decelerations, and those who had an epileptic seizure at delivery were not included in the study, either. The 1- and 5-minute APGAR scores after birth were recorded. Umbilical arterial blood gas samples of the patient groups who had epileptic seizures during pregnancy and who did not were compared with each other and with the control group.

Statistical data was acquired using the Statistical Package for the Social Sciences for Windows version 17.0 (SPSS, Chicago, IL, USA) for Windows program. The mean \pm standard deviation was used as descriptive statistics. Whether continuous variables were normally distributed or not was analyzed using Kolmogorov-Smirnov test. Significance between the groups was assessed by means of independent samples t-test and Anova test. In the assessments, the predicted error rate was $\alpha=0.05$.

\section{Results}

The mean age, mean gestation period (weeks), and mean birth weight of the patients with and without epilepsy included in the study are shown in Table 1. When the three groups were compared with each other, no statistical difference was found regarding the, gestation period, and birth weight $(\mathrm{p}>0.05)$. In all instances, the 1- and 5-minute APGAR scores were found to be $\geq 7$.

While $5(17 \%)$ of the patients who had no history of seizures during pregnancy were not taking antiepileptic drugs, 2 (8\%) were receiving polytherapy and 21 (75\%) were receiving monotherapy. Two (7\%) of the patients with a history of 5 or more seizures during pregnancy were receiving polytherapy, and 25 (93\%) were receiving monotherapy (Table 2).

The distribution of umbilical arterial blood gas values of the patients included in the study is shown in Table 3 . When 55 pregnant women with epilepsy included in the study were compared with 50 pregnant women constituting the control group, although their umbilical arterial blood $\mathrm{pH}$ values were found to be lower, $\mathrm{pCO}_{2}$ values were higher, and $\mathrm{pO}_{2}$ values were lower, no statistically significant difference was found between the groups ( $\mathrm{p}>0.05)$. 
When the control group without epilepsy was compared with the pregnant women without a history of epileptic seizures during pregnancy, no difference was found in umbilical arterial blood gas values ( $\mathrm{p}>0.05)$.

When the patients with a history of 5 or more epileptic seizures during pregnancy were compared with the control group without epilepsy and patients with epilepsy who had no history of seizures during pregnancy, although their umbilical arterial blood $\mathrm{pH}$ values were found to be lower, $\mathrm{pCO}_{2}$ values were higher, and $\mathrm{pO}_{2}$ values were lower, there was no statistically significant difference ( $\mathrm{p}>0.05)$.

Moreover, when other blood gas parameters were assessed, no difference was found between the three groups regarding base excess and $\mathrm{HCO}_{3}$ levels ( $\left.\mathrm{p}>0.05\right)$.

\section{Discussion}

Intrapartum assessment of umbilical cord arterial blood gas values is a decisive method of diagnosis in birth management.

Table 2. Distribution of antiepileptic therapy in patients

\begin{tabular}{|l|c|c|}
\hline & $\begin{array}{c}\text { Pregnant women } \\
\text { with epilepsy who } \\
\text { had no seizures } \\
\text { (n=28) }\end{array}$ & $\begin{array}{c}\text { Pregnant women } \\
\text { with epilepsy } \\
\text { who had at least } \\
\text { 5 seizures } \\
\text { (n=27) }\end{array}$ \\
\hline $\begin{array}{l}\text { No use of antiepileptic } \\
\text { drugs, } n\end{array}$ & 5 & - \\
\hline $\begin{array}{l}\text { Carbamazepine } \\
\text { monotherapy, } n\end{array}$ & 9 & 11 \\
\hline $\begin{array}{l}\text { Lamotrigine } \\
\text { monotherapy, } \mathrm{n}\end{array}$ & 4 & 4 \\
\hline $\begin{array}{l}\text { Valproic acid } \\
\text { monotherapy, } \mathrm{n}\end{array}$ & 2 & 3 \\
\hline $\begin{array}{l}\text { Oxcarbazepine } \\
\text { monotherapy, } \mathrm{n}\end{array}$ & 2 & 1 \\
\hline $\begin{array}{l}\text { Levetiracetam } \\
\text { monotherapy, } \mathrm{n}\end{array}$ & 2 & 1 \\
\hline $\begin{array}{l}\text { Carbamazepine and } \\
\text { levetiracetam } \\
\text { polytherapy, } \mathrm{n}\end{array}$ & - & \\
\hline $\begin{array}{l}\text { Valproic acid and } \\
\text { lamotrigine } \\
\text { polytherapy, } \mathrm{n}\end{array}$ & & \\
\hline
\end{tabular}

In addition, as a retrospective idea about fetal well-being during delivery, it contributes to the management of the neonatal term and to decisions about possible attempts at neonatal resuscitation in this term. Umbilical cord blood gas measurement performed at delivery is an objective indicator of fetal acid-base balance, and it is also accepted as the fetal response to birth (9). When the umbilical cord arterial blood $\mathrm{pH}$ value is $\leq 7.20$, the condition is defined as fetal acidosis; however, a $\mathrm{pH}$ of $\leq 7.0$ is considered pathological acidosis. In term neonates born with an umbilical cord arterial blood $\mathrm{pH}$ of $>7.0$, no increase has been observed in long-term morbidity (10).

As for APGAR scoring, it might be beneficial in distinguishing normal neonates and the ones severely affected by hypoxia. This method of scoring, however, is not sensitive enough to distinguish babies affected to a lesser extent by hypoxia (8). Therefore, as an indicator of intrapartum condition during delivery and neonatal prognosis after delivery, umbilical cord $\mathrm{pH}$ values have been focused on in recent years (11). Umbilical fetal blood gas $\mathrm{pH}$ and other measures are reported to be more valuable in terms of yielding fewer false-positive results in the differential diagnosis. Thus, after delivery, in distinguishing babies exposed to hypoxia, the determination of umbilical cord blood gases is adopted, along with the use of intrapartum electronic fetal monitoring (12).

The answer to the question "Which artery should umbilical cord blood gases be drawn from?" should naturally be the umbilical artery, as it better reveals fetal well-being. The reason for this is that in the case of fetal acidemia and hypoxia, changes first occur in umbilical arterial blood gases. Moreover, when umbilical cord venous blood gas values are at normal levels, acidemia may occur in the umbilical artery (11). Therefore, in this study, umbilical arterial blood gas parameters were analyzed.

When carbon dioxide that has formed on fetal tissues is not eliminated through uteroplacental circulation, $\mathrm{pCO}_{2}$ increases and respiratory acidosis occurs. If fetal tissues are insufficiently oxygenated, the activation of the anaerobic pathways for glucose utilization results in lactic acid accumulation and metabolic acidosis. At delivery, changes occur in factors affecting gas flow in uteroplacental circulation and, according to their significance, in umbilical cord blood gas parameters.

The effects of epileptic seizures during pregnancy on the fetus have always been worrying. Maternal epileptic seizures may cause fetal hypoxia, leading to changes in umbilical arterial blood gas. Generalized tonic-clonic seizures are harmful to the fetus due to the resulting increase in blood pressure, oxygenation, and electrolyte changes during a seizure. In addition,

Table 3. The results of the umbilical arterial blood gas analysis

\begin{tabular}{|c|c|c|c|c|c|}
\hline Group & $\mathbf{p H}$ & $\underset{(\mathrm{mmHg})}{\mathrm{pCO}_{2}}$ & $\underset{(\mathbf{m m H g})}{\mathbf{p O}_{2}}$ & $\underset{(\mathrm{mmol} / \mathrm{L})}{\mathrm{HCO}_{3}}$ & $\begin{array}{l}\text { Base Excess } \\
(\mathrm{mmol} / \mathrm{L})\end{array}$ \\
\hline $\begin{array}{l}\text { Pregnant women with epilepsy who had no } \\
\text { seizures }(n=28)\end{array}$ & $7.24 \pm 0.08$ & $53.1 \pm 11.5$ & $16.1 \pm 5.7$ & $23.3 . \pm 5.1$ & $-4.3 \pm 2.2$ \\
\hline $\begin{array}{l}\text { Pregnant women with epilepsy who had at } \\
\text { least } 5 \text { seizures }(n=27)\end{array}$ & $7.22 \pm 0.03$ & $55.1 \pm 10.2$ & $14.4 \pm 4.26$ & $22.1 \pm 5.0$ & $-4.7 \pm 1.9$ \\
\hline Control group without epilepsy $(n=50)$ & $7.24 \pm 0.05$ & $52.1 \pm 11.2$ & $17.7 \pm 5.21$ & $23.1 \pm 5.0$ & $-4.1 \pm 2.1$ \\
\hline
\end{tabular}


the increase in intrauterine pressure during a seizure may also decrease uteroplacental blood flow (6). It has been shown in cardiotocography follow-ups that in term pregnancy, generalized tonic-clonic seizures cause temporary fetal asphyxia. Fetal bradycardia, a decrease in variability, and decelerations may be observed for 15 minutes following a seizure (6). Fetal damage may be caused by metabolic changes attributable to prolonged generalized tonic-clonic seizures (13). Prolonged generalized tonic-clonic seizures may even result in fetal bradycardia and fetal death, even in the absence of maternal hypoxia (14).

Umbilical arterial blood gas values may not only be affected by such pathological conditions as uteroplacental insufficiency, causing intrauterine growth retardation, but also change depending on gestation period, the mode of delivery, and the type of anesthesia administered. In the relevant literature, it has been pointed out that there is no significant correlation between birth weight and blood gases; however, in cases of intrauterine growth retardation associated with uteroplacental insufficiency, fetal metabolic acidemia may occur (15). In our study, there was no difference between the groups with and without a history of seizures during pregnancy with respect to birth weight, and all cases were in term pregnancy. Studies indicate that umbilical arterial blood gas values in vaginal deliveries were found to be lower compared to those in caesarean section deliveries (16). Therefore, to be able to determine the effects of patients with epilepsy on blood gas, only pregnant women with epilepsy who had a caesarean delivery were included in our study, and the control group consisted of the patients who had an elective caesarean section.

The type of anesthesia administered during caesarean delivery, whether general or regional, does not have an effect on umbilical arterial blood gases (17). However, when the mother is under general or regional anesthesia, increased length of time from uterine incision to delivery (especially an interval of longer than 3-5 minutes) and prolonged exposure to inhalation agents under general anesthesia lead to low APGAR scores and acidosis in neonates (18). In another study, it has been stated that in babies born after a long induction-to-uterotomy and uterotomy-to-delivery time interval, umbilical arterial $\mathrm{pH}$ values and APGAR scores were found to be low (19). In our study, all of our patients delivered their babies under general anesthesia, and in all cases, the time interval from skin incision to the delivery of the baby was recorded to be shorter than 3 minutes. Moreover, not using inhalation agents until the umbilical cord was clamped allowed us to avoid negative effects on blood gas. In term caesarean deliveries, "normal" umbilical arterial blood gas values were indicated as follows: $\mathrm{pH} 7.27$ (7.15-7.38), $\mathrm{pCO}_{2} 49$ (32-68) $\mathrm{mm} \mathrm{Hg}, \mathrm{HCO}_{3} 22.3$ (15.4-26.8) $\mathrm{mEq} / \mathrm{L}$, and base excess -4 (-8.1-0.9) mEq/L (20). Umbilical arterial $\mathrm{pO}_{2}$ values were not found to be associated with any adverse neonatal outcomes (21).

There is a complex relationship between fetal asphyxia (antepartum and intrapartum), neonatal asphyxia, and possible resulting brain damage. The severity, duration, and nature of asphyxia are affected by the cardiovascular compensatory response. Asphyxia is defined as a condition of impaired blood gas exchange, which may lead to progressive hypoxemia and hypercapnia (22). According to the American College of Obstetricians and Gynecologists, it is also a clinical situation of damaging hypoxia and metabolic acidosis (21). Asphyxia may also occur temporarily without causing pathologic sequelae. However, when a fetus is severely affected by asphyxia, it may result in a decrease in oxygenation of tissues, acid accumulation, and metabolic acidosis. A blood gas and acid-base assessment should be carried out for the diagnosis of intrapartum fetal asphyxia. The crucial question for clinicians is "What is the threshold of metabolic acidosis above which fetal morbidity and mortality may occur?"

Low and colleagues have suggested a scoring system aimed at predicting neonatal encephalopathy and defined umbilical arterial base deficits at birth as mild at $4-8 \mathrm{mmol} / \mathrm{l}$, moderate at 8-12 $\mathrm{mmol} / \mathrm{l}$, and severe at greater than 12 (23). It has been shown that the incidence of minor motor and cognitive defects among term neonates exposed to mild antepartum fetal asphyxia increased at the age of 4-8, compared to those not exposed to asphyxia (24). Some criteria have been laid down to define an acute intrapartum hypoxic event as sufficient to be a cause of cerebral palsy. In an umbilical cord arterial blood analysis performed at delivery, $\mathrm{pH}<7$ and base deficit $\geq 12$ have been reported as evidence of metabolic acidosis (21).

In our study, we aimed to clarify whether epileptic seizures that occur during pregnancy are associated with antepartum asphyxia. For this purpose, we made use of the umbilical cord arterial blood gas measurement, which remains one of the most reliable indicators of asphyxia. In our study, when the control group without epilepsy and the pregnant women without a history of epileptic seizures during pregnancy were compared, no difference was found regarding umbilical arterial blood gas values, and it was demonstrated that controlled pregnancies that were complicated by epilepsy were not associated with chronic hypoxia or antepartum asphyxia.

Although the negative effects of prolonged epileptic seizures on the fetus have been revealed, it is obvious that exposure to fetal hypoxia will also increase as the number of seizures increases during pregnancy. In our study, when the pregnant women with a history of 5 or more epileptic seizures during pregnancy were compared with those with epilepsy who had no history of seizures during pregnancy, although there was no statistically significant difference between them, their umbilical arterial blood $\mathrm{pH}$ values were found to be lower, $\mathrm{pCO}_{2}$ values were higher, and $\mathrm{pO}_{2}$ values were lower.

In the relevant literature, it has been demonstrated that the rate of pregnancy complications and adverse perinatal outcomes increases in pregnancies in women with epilepsy. Most of such pregnancies, however, go to full term without problems (25). It has been reported that during pregnancy, $48 \%-57 \%$ of pregnant women with epilepsy have no change in seizure frequency, 25\%-33\% experience an increase, and 9\%-22\% have a decrease in seizure frequency (26). The most important factor that is believed to cause an increase in seizure frequency is to stop taking antiepileptic drugs during pregnancy. Expectant mothers stop taking antiepileptic drugs, especially in the course of the first 3 months of their pregnancy, to avoid potential negative effects of these drugs on their babies. Childbirth is a process in 
which epileptic attacks are triggered. At delivery, the risk of having an attack increases to 9 times as likely. Therefore, great care should be taken at delivery, and the patient should deliver by caesarean section when required. If recurrent seizures occur at delivery, caesarean section should be performed under general anesthesia because of the risk of fetal anoxia.

In conclusion, pregnancies in women with epilepsy pose unique challenges to expectant mothers. The follow-up of pregnant women with epilepsy requires good teamwork between an obstetrician and a neurologist suitably experienced in management issues for such cases. By adopting a balanced approach and monitoring appropriate follow-up of these patients, it is possible to achieve favorable pregnancy outcomes in women with epilepsy-basically the same as those in the general population. As there are potential fetal risks, maternal generalized tonic-clonic epileptic seizures might be alarming. Thus, with the administration of optimal treatment, epileptic seizure control should be provided during pregnancy so as to reduce the risk of convulsions to a minimum. It is recommended that monotherapy for seizures and treatment at the lowest effective dose should be administered to pregnant women with epilepsy in the preconception and prenatal terms.

Ethics Committee Approval: Ethics committee approval was received for this study from the local ethics committee.

Informed Consent: Written informed consent was obtained from patients who participated in this study.

Peer-review: Externally peer-reviewed.

Author contributions: Concept - Ö.Ö.; Design - Ö.Ö.; Supervision - M.E.S.; Resource - F.A.E.; Materials - V.S., A.K.; Data Collection\&/ or Processing - V.S., A.K.; Analysis\&/or Interpretation - Ö.Ö., M.E.S.; Literature Search - Ö.Ö., M.E.S.; Writing - Ö.Ö.; Critical Reviews - C.A.

Conflict of Interest: No conflict of interest was declared by the authors.

Financial Disclosure: The authors declared that this study has received no financial support.

\section{References}

1. Richmond JR, Krishnamoorthy P, Andermann E, Benjamin A. Epilepsy and pregnancy: An obstetric perspective. Am J Obstet Gynecol 2004; 190: 371-9. [CrossRef]

2. Dravet C, Julian C, Legras C, Magaudda A, Guerrini R, Genton P, et al. Epilepsy, antiepileptic drugs, and malformations in children of women with epilepsy: A French prospective cohort study. Neurology 1992; 42 (4 Suppl 5): 75-82.

3. Yerby M, Koepsell T, Daling, J. Pregnancy complications and outcomes in a cohort of women with epilepsy. Epilepsia 1985; 26: 631-5. [CrossRef]

4. Lindhout D, Meinardi H, Meijer JW, Nau H. Antiepileptic drugs and teratogenesis in two consecutive cohorts: changes in prescription policy paralleled by changes in pattern of malformations. Neurology 1992; 42 (4 Suppl 5): 94-110.

5. Nelson KB, Ellenberg JH. Maternal seizure disorder, outcome of pregnancy, and neurologic abnormalities in the children. Neurology 1982; 32: 1247-54. [CrossRef]
6. Teramo K, Hiilesmaa V, Bardy A, Saarikoski S. Fetal heart rate during a maternal grand mal epileptic seizure. J Perinat Med 1979; 7: 3-6. [CrossRef]

7. ACOG Committee on Obstetric Practice. ACOG Committee Opinion No. 348, November 2006: Umbilical cord blood gas and acid-base analysis. Obstet Gynecol 2006; 108: 1319-22. [CrossRef]

8. Yeomans ER, Hauth JC, Gilstrap LC, Strickland DM. Umbilical cord $\mathrm{pH}, \mathrm{PCO} 2$ and bicarbonate following uncomplicated term vaginal deliveries. Am J Obstet Gynecol 1985; 151: 798-800. [CrossRef]

9. Goldaber KG, Gilstrap LC. Correlations between clinical events and umbilical cord blood acid-base and blood gas values. Clin Obstet Gynecol 1993; 36: 47-59. [CrossRef]

10. Gordon A, Johnson JW. Value of umbilical blood acid-base studies in fetal assessment. J Reprod Med 1985; 30: 329-36.

11. Benian A, Uludağ S, Atış A, Gök M, Madazıı R. Analysis of umbilical cord blood acid-base status at birth. Cerrahpasa J Med 2002; 33: 236-44.

12. Gilstrap LC. Fetal Acid-base Balance. In: Creasy RK, Resnik R, editors. Maternal-Fetal Medicine. Philadelphia: WB Saunders; 1998. p. 331.

13. Minkoff H, Schaffer R, Delke I, Grunebaum N. Diagnosis of intracranial hemorrhage in utero after a maternal seizure. Obstet Gynecol 1985; 65 (3 Suppl): S22-24.

14. Hiilesmaa VK, Teramo K, Bardy AH. Social Class, Complications, and Perinatal Deaths in Pregnancies of Epileptic Women: Preliminary Results of the Prospective Helsinki Study. In: Janz D, editors. Epilepsy, Pregnancy, and the Child. New York: Raven Press; 1982. p. 87-90.

15. Atalla RK,Abram SK, Bell SC, Taylor DJ. Newborn acid-base status and umbilical cord morphology. Obstet Gynecol 1998; 92: 865-8. [CrossRef]

16. Thorp JA, Dildy GA, Yeomans ER, Meyer BA, Parisi VM. Umbilical cord blood gas analysis at delivery. Am J Obstet Gynecol 1996; 175: 517-22. [CrossRef]

17. $\mathrm{Li} \mathrm{CH}$, Zhu CX, He J. Effects of general anesthesia for cesarean section on infants. Zhonghua Fu Chan Ke Za Zhi 2006; 41: 162-4.

18. Harrad J, Howell P. General anaesthesia for caesarean section. Curr Anaesth Crit Care 2000; 11: 66-72. [CrossRef]

19. Dahlgren G, Granath F, Pregner K, Rösblad PG, Wessel H, Irestedt L. Colloid vs. crystalloid preloading to prevent maternal hypotension during spinal anesthesia for elective cesarean section. Acta Anaesthesiol Scand 2005; 49: 1200-6. [CrossRef]

20. Gregg AR, Weiner CP. "Normal" umbilical arterial and venous acid-base and blood gas values. Clin Obstet Gynecol 1993; 36: 24-32. [CrossRef]

21. American Academy of Pediatrics, American College of Obstetricians and Gynecologists. Neonatal encephalopathy and cerebral palsy: defining the pathogenesis and pathophysiology. Elk Grove Village (IL): AAP; Washington, DC: ACOG; 2003.

22. Bax M, Nelson KB. Birth asphyxia: A statement. World Federation of Neurology Group. Dev Med Child Neurol 1993; 35: 1022-4. [CrossRef]

23. Low JA, Lindsay BG, Derrick EJ. Threshold of metabolic acidosis associated with newborn complications. Am J Obstet Gynecol 1997; 177: 1391-4. [CrossRef]

24. Handley-Derry M, Low JA, Burke SO, Waurick M, Killen H, Derrick EJ. Intrapartum fetal asphyxia and the occurrence of minor deficits in 4- to 8-year-old children. Dev Med Child Neurol 1997; 39: 508-14. [CrossRef]

25. Morrell MJ. Reproductive and metabolic disorders in women with epilepsy. Epilepsia 2003; 44 (Sup 4): 11-20.

26. Sabers A, aRogvi-Hansen B, Dam M, Fischer-Rasmussen W, Gram L, Hansen M, et al. Pregnancy and epilepsy: A retrospective study of 151 pregnancies. Acta Neurol Scand 1998; 97: 164-70. [CrossRef] 